\title{
Liability of media companies for mental harm suffered by journalists reporting on traumatic events
}

\author{
Marco Rizzi ${ }^{*}$
}

\section{Introduction}

In a widely reported decision of February 2019, Judge O'Neill of the County Court of Victoria awarded $\$ 180,000$ damages to a journalist of The Age newspaper. The plaintiff, anonymously referred to as 'YZ' in the judgment, had been working at the paper as a crime reporter between 2003 and 2009, and subsequently as a court reporter from 2010 to 2013. She successfully established that she had suffered post-traumatic stress disorder ('PTSD') as a result of prolonged and repeated exposure to crime scenes and criminal trials in the absence of an adequate system which her employer should have had in place 'to enable her to deal with the trauma of the work'. ${ }^{1}$ According to reports, this was the first time a journalist has been able to recover for this type of loss, not only in Australian courts, but around the world. ${ }^{2}$ On 19 December 2019 the Court of Appeal of Victoria comprising Niall, Forrest and Emerton JJA, while partially allowing the appeal, substantially upheld the first instance decision. ${ }^{3}$ Indeed, their Honours found no errors of law in the reasoning of Judge 0'Neill, which they simply clarified where needed, and only partially overturned the scope of his initial finding. The case thus warrants attention because of its novelty and the weight carried by a decision of a state's highest court - which finally provides a remedy for a type of professional hazard that journalists have been drawing attention to for quite some time.

\section{Context and significance}

Journalists, and in particular reporters and photographers, have been advocating for an adequate recognition of the risks to mental health inherent to their profession for a long time. A quick review of sectoral literature over the past 15 years shows a cyclical recurrence of the issue in both academic writings and investigative reporting. ${ }^{4}$ Journalists have been

\footnotetext{
${ }^{*}$ Senior Lecturer, University of Western Australia, UWA Law School.

${ }^{1}$ YZ (a pseudonym) v The Age Co Ltd [2019] VCC 148, [2] ('YZ').

2 Farz Edraki and Damien Carrick, "Trauma of News Journalism in Focus after The Age Found Responsible for Reporter's PTSD', ABC News (online, 22 March 2019) <https://www.abc.net.au/news/2019-03-22/ex-agejournalist-awarded-damages-for-ptsd-world-first/10896382>; Matthew Ricketson and Alexandra Wake, 'Media Companies on Notice over Traumatised Journalists after Landmark Court Decision', The Conversation (Web Page, 6 March 2019) <http://theconversation.com/media-companies-on-notice-over-traumatisedjournalists-after-landmark-court-decision-112766>.

${ }^{3}$ The Age Co Ltd v YZ (a pseudonym) [2019] VSCA 313 ('The Age').

${ }^{4}$ Scholarly sources include: River J Smith, Susan Drevo and Elana Newman, 'Covering Traumatic News Stories: Factors Associated with Post-Traumatic Stress Disorder Among Journalists' (2018) 34(2) Stress and Health 218; Mina Lee, Eun Hye Ha and Jung Kun Pae, 'The Exposure to Traumatic Events and Symptoms of
} 
found to be particularly vulnerable to PTSD and other stress-related mental illnesses when the job involves exposure to graphic and distressing events or their aftermath, as well as close contact with victims, survivors or relatives of traumatic events such as violent crimes, acts of war or terror, natural disasters, or refugee crises. However, this known vulnerability has failed to translate into judicial acknowledgment of the mental pains and struggles of those reporting on challenging stories. In Australia, this lack of acknowledgment was particularly evident in the well-known case of $A Z v$ The Age [No 1] ('AZ'), 5 another case arising in Victoria against the same media company. In that case the plaintiff claimed that her career as a photographer over the course of approximately 20 years had sensitised her to the risk of mental harm. In 2003 she was sent by her employer to photograph the families of victims of the 2002 Bali bombings as they were being interviewed 1 year after the attacks. The 'heart-wrenching' content of the interviews, coupled with the lack of support provided by The Age to assist her with the emotional and psychological impact these interviews had on her mental wellbeing, allegedly caused her to suffer PTSD and severe depression. ${ }^{6}$ The case failed on the grounds that the psychiatric injury, in the circumstances, was not foreseeable and as such no duty was owed. ${ }^{7}$

Generally, it is well-established that whether an employer owes their employees a duty of care extending beyond the provision of a physically safe working environment to encompass psychological safety is a question of scope and not of existence of that duty. ${ }^{8}$ The Australian case law has proved particularly restrictive in its willingness to include stress-related psychiatric injury occurring in the course of employment within the scope of an employer's duty of care, a reluctance fully fleshed out in Koehler v Cerebos (Australia) Ltd ('Koehler'). ${ }^{9}$ In that decision, the High Court notoriously linked the scope of the employer's duty in relation to their employees' mental wellbeing to the content of the contract of employment effectively exonerating employers from liability for mental harm arising out of the normal discharge of an employee's accepted contractual duties. The decision in $Y Z$ is of interest because damages have been awarded precisely for mental harm allegedly arising out of the reporter's discharge of contractual duties, in an effort to recognise the inherent risks of the

\footnotetext{
Posttraumatic Stress Disorder among Korean Journalists' (2018) 19(9-10) Journalism 1308; Tess Browne, Michael Evangeli and Neil Greenberg, 'Trauma-Related Guilt and Posttraumatic Stress Among Journalists' (2012) 25(2) Journal of Traumatic Stress 207; Gretchen Dworznik, 'Factors Contributing to PTSD and Compassion Fatigue in Television News Workers' (2011) 1(1) International Journal of Business, Humanities and Technology 22. Other reports include: Joe Hight and Frank Smyth, 'Tragedies \& Journalists: A Guide for More Effective Guide' (Dart Center for Journalism \& Trauma, 2003) 16; Frederik Joelving, 'When the News Breaks the Journalist: PTSD', Reuters (online, 18 December 2010) 1.

.<http://www.reuters.com/article/2010/12/17/us-ptsd-reporter-idUSTRE6BG3NG20101217>.

5 [2013] VSC 335 ('AZ').

${ }^{6}$ For an exhaustive commentary on the case, see Peter Handford, 'Liability for Work Stress: Koehler Ten Years On' (2015) 39(2) University of Western Australia Law Review 180.

${ }^{7} A Z$ (n 5) [233].

8 Peter Handford, Tort Liability for Mental Harm (Lawbook, $3^{\text {rd }}$ ed, 2017) 641.

${ }^{9}$ (2005) 222 CLR 44 ('Koehler').
} 
profession to the mental wellbeing of its practitioners. The appellate judgment in The Age confirmed this important legal development by upholding the thrust of Judge O'Neill's reasoning, and only allowing part of the appeal where the facts did not support the first instance decision.

\section{Facts and decision}

In her claim, the plaintiff alleged that repeated exposure 'to traumatic events and traumatic stress' 10 caused her to suffer PTSD and that 'at all material times the defendant knew or ought to have known that by reason of that exposure, the plaintiff could develop psychological injury'. ${ }^{11}$ The particulars of the breach of duty as outlined in the judgment include a long list of failures by The Age that essentially revolved around the absence of an adequate system to prevent and respond to the onset of foreseeable mental harm in the journal's reporters. These failures included the lack of an adequate peer support program, the lack of adequate policies or procedures, the absence of appropriate training for both the plaintiff and other employees, and the failure to provide adequate follow-up and responsive measures once the defendant became aware of the plaintiff being at increased risk of psychiatric harm. The Court of Appeal helpfully summarises the content of the duty of care as formulated by Judge $0^{\prime} \mathrm{Neill}$ at first instance:

the content of the duty was ... focused and centred around training, peer support and rotation. Subject to one qualification, those matters were reasonable steps for the employer to adopt and were nether too vague or unworkable. The qualification relates to whether managers were required to proactively investigate or assess the plaintiff's mental health status. ${ }^{12}$

The facts of the case are as follows. ${ }^{13}$ Between 2003 and 2009, YZ worked as a crime reporter. She covered a number of gruesome crime scenes and investigated several horrible acts of violence, which caused her prolonged exposure to trauma. A tipping point was her coverage of the murder of Darcey Freeman, a 4-year-old child thrown off the Westgate Bridge. The murder scene was particularly horrific. When she returned to the newsroom on the day of attending the scene, she shared with her colleagues: 'I'm done, I can't do this anymore. I have had enough of death and destruction'. ${ }^{14}$ Around the same time, in 2009, she was referred to psychotherapy by her general practitioner. She had already reached out to The Age's Employee Assistance Program ('EAP') in 2007; however, the service was overbooked, and she was not assisted for several weeks. Once she finally started to receive counselling she

\footnotetext{
${ }^{10} \mathrm{YZ}$ (n 1) [4].

${ }^{11}$ Ibid [6].

12 The Age (n 3) [150] (emphasis added).

${ }_{13} Y Z$ (n 1) [13]-[51].

${ }^{14}$ Ibid [28].
} 
quickly realised that the counsellors lacked understanding of the nature and demands of her job and the levels of pressure the newsroom put on reporters. ${ }^{15}$

YZ complained to her employer following her coverage of the Freeman murder, which earned her a transfer in February 2009 to the sports section of the newspaper. ${ }^{16}$ She happily reported on sports events and recovered her mental wellbeing until April 2010, when she was effectively nudged into accepting a position as court reporter - a position she was not seeking and did not want. ${ }^{17}$ She then worked as a court reporter, principally covering Supreme Court cases, until 2013. In that period she reported on a number of trials, including that of the Freeman homicide. She was exposed to distressing scenes including horrific testimonies, graphic evidence of violent crimes and the pain and suffering of distraught family members of victims. ${ }^{18}$ After trial, Judge O'Neill described the plaintiff's evidence as 'chilling', 19 and concluded that her exposure to trauma was substantial. ${ }^{20}$

In her claim, YZ alleged that repeated exposure 'to traumatic events and traumatic stress' 21 caused her to suffer PTSD and that 'at all material times the defendant knew or ought to have known that by reason of that exposure, the plaintiff could develop psychological injury'.22 The particulars of the breach of duty as outlined in the County Court decision include, as recalled above, a long list of failures by The Age that resulted in the absence of an adequate system to prevent and respond to the insurgence of foreseeable mental harm in the journal's reporters.

The trial judge's decision was sensitive to the disturbing nature of the facts and the severe level of psychological damage suffered by the plaintiff in the circumstances. In a surprisingly long judgment, Judge O'Neill held that the type of harm suffered by YZ was foreseeable and within the scope of The Age's duty of care. He concluded that a duty of care was indeed breached, and that the breach was causative of the harm, leading to an award of general damages for $\$ 180,000$. The Age filed an appeal essentially based on two substantive grounds. First, that the scope of duty of the employer postulated by Judge O'Neill was too wide, insufficiently identified in the evidence and encroaching on the plaintiff's autonomy and privacy. Secondly, that The Age had not actually breached its duty of care, absent a clear counterfactual in the evidence adduced in Judge O'Neill's reasoning. ${ }^{23}$ The Court of Appeal

\footnotetext{
15 Ibid [34].

${ }^{16}$ Ibid [108]-[109].

17 Ibid [37].

18 Ibid [39]-[48].

${ }^{19}$ Ibid [49].

${ }^{20}$ Ibid [51].

${ }^{21}$ Ibid [5].

22 Ibid [6].

${ }^{23}$ The Age (n 3) [98]
} 
partially allowed the second ground of appeal, setting aside the order for damages and remitting the matter to the trial judge in light of the fact that Judge O'Neill in his conclusion did not differentiate between the two distinct periods of activity as crime reporter (20032009), and as court reporter (2010-2013). Indeed, their Honours were unpersuaded that the steps identified in the primary judge's reasons would have, on a balance of probability, averted the risk of PTSD in the initial period 2003-2009. On the other hand, the trial judge's findings that the defendant's negligence during the second period, 2010-2013 caused the plaintiff's PTSD, were upheld. ${ }^{24}$

\section{Reasoning and comments}

\section{a. General remarks}

As a preliminary observation it should be noted that the claim was brought as a breach of contract of employment or 'alternatively breach of the duty of care'. ${ }^{25}$ The claim was ultimately treated as a negligence claim for reasons of simplicity and on the grounds that breach of contract would not raise any different legal principle, nor entitle the plaintiff to different heads of damage. ${ }^{26}$

What is noticeably lacking in both the judgment at first instance and the appellate decision is a discussion of the applicability of the Victorian workers' compensation legislation, which has limited the rights of workers to make negligence claims at common law. In particular, the Accident Compensation Act 1985 (Vic) and the Workplace Injury Rehabilitation and Compensation Act 2013 (Vic) both set as a requirement for an action in damages that the injury be 'serious'. ${ }^{27}$ This issue should have been addressed by the trial judge because either the harm suffered by YZ was not a serious injury, in which case it should have been appropriately brought under the workers' compensation scheme, or if it was in fact a serious injury, given the plaintiff's choice not to pursue the case under the special legislation, the case should arguably have been adjudicated on the basis of Pt X of the Wrongs Act 1958 (Vic), which departs from the common law especially as regards causation (as discussed below). The trial judge also elected not to discuss the applicability to the case of the Workers Compensation Act 1958 (Vic), which again should in theory displace an action in negligence. ${ }^{28}$ The uneasy relationship between general negligence claims and special compensation

\footnotetext{
${ }^{24}$ Ibid [11]-[12].

${ }^{25} \mathrm{YZ}$ (n 1) [4].

${ }^{26}$ Ibid [4] n 2.

${ }^{27}$ Accident Compensation Act 1985 (Vic) s 134AB; Workplace Injury Rehabilitation and Compensation Act 2013 (Vic) s 327.

${ }^{28}$ Wrongs Act 1958 (Vic) s 45(1)(c). See also Handford, Tort Liability for Mental Harm (n 8) 654; and Mark Leeming, The Statutory Foundations of Negligence (Federation Press, 2019) 33 [2.7]. It is worth noting that in other jurisdictions the applicability of the civil liability legislation to work-related injuries has given rise to some confusion, see, eg, the New South Wales case of Miskovic v Stryke Corp Pty Ltd [2011] NSWCA 369, discussed in Handford, 'Liability for Work Stress: Koehler Ten Years On' (n 6) 170.
} 
schemes for workers' injuries receives no assistance from this decision; with respect, this may be one of the weaker aspects of the judgment and one that was not addressed by the Court of Appeal either..

\section{b. Foreseeability of harm}

The trial judgment follows the traditional tripartite structure of the tort of negligence. A slightly dubious point was made at the outset with respect to foreseeability of harm: the court, quoting Kohler, ${ }^{29}$ suggested that the foreseeability of psychiatric harm to the particular employee needs to be established, rather than foreseeability of harm to employees in general. ${ }^{30}$ While this is certainly true, the wording may suggest that the foreseeability test is a subjective one, based on the characteristics of the particular employee. This is not the case. Indeed, the test remains an objective one and, as established in Tame $v$ New South Wales, ${ }^{31}$ it involves assessing whether it is foreseeable that a person in the plaintiff's circumstances would suffer psychiatric harm. This aspect is clearer in the appellate decision, where Kohler is discussed in less ambiguous terms. ${ }^{32}$

The Court was satisfied that the psychiatric harm to the reporter was foreseeable on the basis of three separate sets of reasons. Firstly, that the defendant ought to have had knowledge of the risks of mental harm to their employees at the time the plaintiff first started working at The Age in 2003, as there were multiple studies and reports available at the time illustrating such risks - not to mention that it should have been reasonably obvious to an employer such as The Age that reporting on criminal events can be inherently traumatic. ${ }^{33}$ Secondly, that the defendant was well aware of the symptoms suffered and of the complaints filed by the plaintiff between 2003 and 2009 when she worked as a crime reporter. ${ }^{34}$ Finally, that the defendant was aware of the plaintiff's symptoms and complaints between 2010 and 2013 when she was reassigned to Supreme Court reporting. ${ }^{35}$ Interestingly, Judge 0’Neill distinguished this case from the precedent in $A Z$ (while recognising that the psychiatric injury in that case 'arose in circumstances not dissimilar') on the basis that in that case the Court had doubts 'as to whether the plaintiff had attended all of the scenes of trauma described in her evidence'. ${ }^{36}$ Exposure to trauma in YZ's case was well-documented and, therefore, never really at issue, as also confirmed by the appellate decision where the issue is briefly discussed without putting into question the trial judge's findings.

\footnotetext{
${ }^{29}$ Kohler (n 9) [35].

30 YZ (n 1) [57]-[61], referring to Koehler (n 8); and Hegarty v Queensland Ambulance Service (2007) Aust

Torts Reports 81-919 in particular.

31 (2002) 211 CLR 317.

32 The Age (n 3) [105]-[106].

${ }^{33} \mathrm{YZ}$ (n 1) [67]-[97], and [128].

${ }^{34}$ Ibid [98]-[113].

35 Ibid [114]-[127].

${ }^{36}$ Ibid [63].
} 
An important factor that influenced the decision in $A Z$ was the notion developed in Koehler that, where a plaintiff agrees to perform certain contractual duties, there is little reason to suspect that they may be at risk of psychiatric injury. ${ }^{37}$ As some commentators have put it: 'the contractual agreement of the employee to perform the work represented her willingness to complete her contract of employment' and this was 'inconsistent with reasonable foreseeability of mental ill-health on her part'.38 One of the most appealing aspects of the judgment in $Y Z$ (and maintained at appellate level in The Age) is the departure from such a deeply-rooted underlying philosophy to embrace a more modern and socially aware judicial approach to the issue of mental wellbeing in the media workplace. In particular, the level of respectful engagement with which his Honour discusses the existing academic literature on PTSD and journalism ${ }^{39}$ is to be welcomed as a positive development towards more mature and less inwards-oriented approaches to matters that, by their very nature, transcend the inner mechanisms of the law and should not be resolved by mere adherence to established doctrines and principles (such as, in the realm of contracts, that of autonomy). ${ }^{40}$ This decision recognises, stigmatises and ultimately sanctions, on one hand, the imbalance of power between employer and employee in the difficult space of mental health and wellbeing, and on the other hand the difficult working environment (a very 'blokey' one in the plaintiff's words) ${ }^{41}$ and culture (which a trial witness described as 'very much a culture of "get on with it"') ${ }^{42}$ that characterise media newsrooms. This rather bold judicial chastising is particularly apparent in the first instance discussion of scope and breach of duty. The partial overturning on appeal, far from diminishing this finding, only qualifies with greater clarity the contours of what constitutes breach of an employer's duty in this context.

\section{c. Scope of duty and breach - what is what?}

In approaching the question of scope at trial, Judge O'Neill refers to the High Court decision in Liftronic Pty Ltd v Unver ${ }^{43}$ where it was emphasised that, in Australia, the duties employers owe their employees 'include affirmative attention to the issue of accident prevention'. ${ }^{44}$ In this instance, while the Court found The Age to have been reactive to the plaintiff's mental health deterioration, it concluded that the steps taken by the media company were

\footnotetext{
${ }^{37}$ Ibid [56].

${ }^{38}$ Pam Stewart and Anita Stuhmcke, Australian Principles of Tort Law (Federation Press, $4^{\text {th }}$ ed, 2017) 453.

$39 Y Z$ (n 1) [68]-[91].

40 On the fallacies of consent in contract law, see Andrew Robertson, 'The Limits of Voluntariness in Contract' (2005) 29(1) Melbourne University Law Review 179.

${ }^{41} Y Z$ (n 1) [105], [140].

42 Ibid [112].

43 (2001) 179 ALR 321.

44 Ibid 343 [85].
} 
noticeably lacking in proactiveness. ${ }^{45}$ Specifically, his Honour listed a number of measures, which in his view constitute the scope of the employer's liability in the circumstances, that the newspaper ought to have taken and did not take, thereby breaching their duty of care. These measures included: 46

- training new journalists to prepare them for the types of traumas they would be likely to experience, as well as to alert them to the typical signs and symptoms that can arise as a result of the work;

- training senior staff to enable them to recognise symptoms in reporters working on traumatic events;

- introducing a peer support program with trained volunteers to assist journalists struggling with the effect of trauma (alongside the professional service offered by psychologists);

- ensuring prompt availability of EAP counsellors for individuals particularly at risk (such as the plaintiff, who had to wait for weeks before she could have an appointment);

- taking steps to change the 'get on with it culture' that permeates the newsroom to create an environment where senior management encourages open discussion about the impact of trauma;

- providing meaningful opportunity to change working area when an employee is at risk of mental harm (removing them from the trauma). This indeed happened in 2009, but the court here was satisfied that 'careful management' would have assisted in taking action more promptly; and

- not transferring an employee who is known to be at risk of psychiatric injury to a delicate area of reporting as happened to the plaintiff in 2010 when she was nudged into the position of court reporter.

Two observations can be made regarding the identification of the precautions as laid out by the trial judge. First, the level of specificity of the proposed list of measures runs the risk of conflating scope with breach of duty. Indeed, the list falls under the paragraph titled 'What was the scope of the duty of care owed by The Age and what measures could have been taken to avoid injury?', which runs separate from the following 'Was there a breach of the duty such as to cause injury?'. The High Court has expressly warned against such a risk and has repeatedly stated that the proper identification of the scope of a duty of care must always maintain a recognisable level of abstraction, short of which it becomes a mere question of fact (which is appropriately discussed as a matter of breach). ${ }^{47}$ However, it is worth recalling

\footnotetext{
${ }^{45} Y Z$ (n 1) [159].

${ }^{46}$ Ibid [162].

${ }^{47}$ Kuhl v Zurich Financial Services Australia Ltd (2011) 243 CLR 361, [21] French CJ and Gummow J 'the formulated duty must neither be so broad as to be devoid of meaningful content [12], nor so narrow as to obscure the issues required for consideration'.
} 
that Judge O'Neill, when tackling the issue of breach, refers to the employer's duty of care as encompassing essentially training, peer support and rotation of employees' duties, so that the judgment in the end arguably maintains a sufficient level of abstraction to keep the two elements distinct. ${ }^{48}$ Secondly, in compiling the list of measures that should have been put in place by the employer, and in his subsequent assessment of breach, Judge O'Neill did not separate the two periods under scrutiny, namely the period 2003-2009 when the plaintiff was working as a crime reporter, and the period 2010-2013 when she was working as a court reporter. This reduction ad unum of the case's complex factual background is rather odd in consideration of the very nature of the measures laid out as falling within the scope of The Age's duty, as promptly picked up by the Court of Appeal.

The Court of Appeal's reasoning on scope and breach of duty is essentially based on the reading of two precedents from the Courts of Appeal of, respectively, Queensland and New South Wales: Hegarty $v$ Queensland Ambulance Service ('Hegarty') ${ }^{49}$, and State of New South Wales $v$ Briggs ('Briggs') ${ }^{50}$. Both decisions, particularly in the judgments of Keane JA in Hegarty and Leeming JA in Briggs, focused on the task of making sure that the scope of the duty of care in work-related psychiatric injury did not expand beyond what can be legitimately expected from a reasonable employer as well as accepted by a reasonable employee. A crucial passage from Hegarty cited in The Age makes the point in no uncertain terms:

In cases of apprehended psychiatric injury, unlike cases concerned with the amelioration of physical risks in the workplace, important values of human dignity, autonomy and privacy are involved in the formulation of a reasonable system of identification of psychiatric problems which may warrant an employer's intervention and the making of a decision to intervene. ${ }^{51}$

While undoubtedly paramount, the respect of an employee's privacy and autonomy should never translate into a de facto blanket immunity for employers who fail to take proactive steps towards the safeguard of their work force's mental wellbeing. What sets the decision in The Age apart from its influential predecessors is the fact that such concern is explicitly voiced by the court in the following admonition:

\footnotetext{
${ }^{48} Y Z$ (n 1) [184]; The Age (n 3) [150].

49 [2007] QCA 366.

50 (2016) 95 NSWLR 467.

${ }^{51}$ Hegarty (n 49) [45].
} 
Care must be taken to ensure that solicitude for an employee's privacy does not overwhelm those other considerations that give rise to a meaningful duty of care to avoid injury. ${ }^{52}$

The Court was most likely inspired by the dissenting words of McColl JA in Briggs, where her Honour said:

the solicitude the 'employer' must exhibit concerns an actual, or potential, workplace injury. The fact that it entails a worker's mental health does not immunise it from the employer's responsibility to discharge the relevant duty of care. Nor, with respect, should it be characterised as an intrusion into an employee's private life. ${ }^{53}$

In putting their own guideline into practice in The Age, their Honours found that focusing an employer's duty around training, peer support and rotation of duties was neither too vague nor invasive of the employee's privacy and autonomy as argued by the appellant. This finding must be subject to the important qualification that the reasoning on scope of duty has to move forward from the moment the plaintiff started her duties as employee, and not backwards from the time of her injury. ${ }^{54}$ In this particular context, the Court of Appeal underlined that the proactive steps required from the employer to take reasonable care in protecting their employee's mental health should not extend to a broad requirement 'to proactively investigate or assess the plaintiff's mental health status'. 55 While such a requirement would indeed stretch the scope of duty too far, the Court correctly observed how this was not the way in which Judge O'Neill had formulated the duty of care at trial.

The only significant point of departure in the reasoning of the Court of Appeal from the findings of the trial judge relates to the failure by Judge O'Neill to distinguish between the first period of activity as crime reporter (2003-2009) and the second period as court reporter (2010-2013). Having identified the scope of the duty of care as encompassing training (of management and personnel), peer support and rotation, the Court notes that better training than the minimal training offered by The Age at the time may have alerted management to the progressive deterioration of the plaintiff's mental wellbeing. This duty to train, however, would have 'entailed no more than to ensure managers and editors were trained to identify and refer at risk employees to appropriate professional care'. ${ }^{56}$ Expecting The Age's management to gain knowledge of the details of the plaintiff's deteriorating

\footnotetext{
${ }^{52}$ The Age (n 3) [131].

${ }^{53}$ Briggs (n 50) 476 [28].

54 Which is the essence of the reasonings of Keane JA in Hegarty (n 49) and Leeming JA in Briggs (n 50).

55 The Age (n 3) [150].

56 Ibid [176].
} 
wellbeing, and thereby take positive action such as rotating her away from crime reporting, would have required them to make inquiries into her private life at such a level that would have resulted in unwarranted encroachment upon the employee's privacy and autonomy particularly since she was very good at her job and enjoying it at the time. ${ }^{57}$ The only effective way to address the cause of her deteriorating mental health would have been to move her away from crime reporting, however, nothing in the evidence suggests that the plaintiff was seeking to be rotated out of that job until the Darcey Freeman murder in 2009, after which she was indeed moved to sports reporting. Moreover, the plaintiff was receiving professional assistance through EAP, a private psychologist and her General Practitioner since 2007, and still had not been seeking rotation until 2009 (nor was it recommended to her). ${ }^{58}$ Therefore, the reasoning convincingly concludes, The Age had not breached their duty of care to the plaintiff when they failed to rotate her out of crime reporting before 2009, and while other aspects of the duty of care (such as providing appropriate training and peer support programmes) may indeed have been breached, they would not have prevented the injury from occurring had they been in place. ${ }^{59}$

The situation was very different in 2010 when the managers and editors at The Age were well aware of the plaintiff's mental health condition. In those circumstances, rotating her back to a traumatic post such as court reporting was found to be clearly negligent and causative of a significant deterioration in the plaintiff's mental health. ${ }^{60}$ Indeed, as acknowledged by their Honours, the most significant proportion of the damage incurred by the plaintiff occurred as a resulted of her move to court reporting in 2010, to the extent that the damages awarded at first instance, while in need of being reassessed, might only change minimally if at all. 61

\section{d. Causation}

The trial judge in $Y Z$, having identified a broad scope of duty, and being satisfied that the duty had been breached by The Age, concluded with a brief discussion of causation, which was essentially resolved by reference to the old common law approach delineated in March $v E$ \& MH Stramare Pty Ltd. ${ }^{62}$ While reference to the 'but for' test is largely uncontroversial, his

subsequent reliance on a 'commonsense and practical approach to causation' 63 is unconvincing for two reasons.

\footnotetext{
57 Ibid [171] and [190].

58 Ibid [176].

59 Ibid [205].

${ }^{60}$ Ibid [183]-[186], and [208].

61 Ibid [211].

62 (1991) 171 CLR 506.

${ }^{63} Y Z$ (n 1) [185].
} 
The first has to do with the relationship between the common law of negligence and its current statutory basis. As suggested above, the interplay between the common law, the civil liability legislation and the special statutory schemes for work-related injuries remains somewhat unsettled, particularly as regards mental harm suffered as a result of the discharge of employment duties. It is therefore difficult to establish with certainty which regime should apply. That notwithstanding, it would seem sensible to maintain some basic coherence in the interpretation of the fundamental elements of the tort of negligence. With the civil liability legislation having adopted, in s 51 of the Wrongs Act, the Ipp Report's position that causation is comprised of two distinct components of factual causation and scope of liability, 64 it is rather unclear on what basis should causality continue to rest on 'commonsense'. ${ }^{65}$ It is worth noting here that this point of law was not discussed on appeal in The Age, which can be characterised as a missed opportunity from a doctrinal perspective.

The second reason to question the trial judge's approach to causation in $Y Z$, and one that informs the reasoning of the Court of Appeal on this point, has to do with the fact that, while commonsense in general 'gives courts and parties to negligence claims very little guidance about when negligent conduct will be considered to have caused harm', 66 this is particularly the case in matters involving complex medical issues such as psychiatric illnesses. To argue, as the trial judge did in $Y Z$, that on the basis of a commonsense appreciation of the facts it is more likely than not that the plaintiff would not have suffered PTSD had The Age put in place the measures falling within the scope of their duty, is an unwarranted oversimplification of the matter which did a disservice to the Court's own and more sophisticated findings on scope and breach of duty. Unsurprisingly, it is precisely the trial judge's reliance on common sense that allowed the Court of Appeal to overrule the trial judge on something that, prima facie, may have appeared as a finding of fact - that The Age's conduct caused the plaintiff's PTSD. Indeed, because those findings were based only on common sense (as opposed to a more stringent application of the 'but for' or 'necessary condition' test, which would at least have required the trial judge to rely on credible inferences), their Honours explained:

they are not findings of a kind that this Court can overturn only if satisfied that they are glaringly improbable or contrary to compelling inferences. Rather, they

\footnotetext{
${ }^{64}$ Commonwealth of Australia, Review of the Law of Negligence (Final Report, 2002) 109 [7.26]: 'Despite this appeal to commonsense, it is accepted that causation has two aspects' (factual causation and scope of liability).

65 See on this point Leeming (n 24) 70 [4.9]. On the inappropriate conflation of the two tests at common law, see also Wallace v Kam (2013) 250 CLR 375, 381 [11]:

the application of the first question, and the existence of the second, have been obscured by traditional expressions of causation for the purposes of the common law of negligence in the conclusory language of 'directness', 'reality', effectiveness', and 'proximity'.

${ }^{66}$ Leeming (n 28) 108 [7.25].
} 
involve an assessment of what is likely to have happened had steps been taken by the employer. ${ }^{67}$

Had the trial judge adhered to a more appropriate test of causation, he arguably would have reached the same (and more convincing) conclusion as the Court of Appeal, and it is disappointing that their Honours did not seize this opportunity to clarify the steps of the causal inquiry for future first instance decisions that may well arise as a result of this case.

\section{Conclusion}

In $Y Z$ a court of law recognised for the first time that media companies may be liable to their journalists for the mental harm they suffer as a result of the trauma they are exposed to in the course of their employment. The main findings have been upheld by the Court of Appeal of Victoria in The Age. This important recognition comes after very detailed discussions of the foreseeability of this type of harm and of what can legitimately be expected from a reasonable employer in the circumstances. The trial judge's reasoning, as qualified by the Court of Appeal's clarifications regarding scope and breach of duty, is to be welcomed as a positive development in the otherwise restrictive domain of work-related psychiatric injuries in Australia. It is reasonable to expect this case to have an impact on the profession; for example, by paving the way for more claims brought forward by aggrieved reporters. More broadly, the decision places higher expectations on media companies in their handling of mental wellbeing in the workplace. Hopefully the next time a reporter brings such a claim, there will also be the opportunity to consider the numerous unresolved legal issues that this important case left open. Judicial guidance would be particularly welcome as regards the interaction between the common law and statutory schemes in work-related mental harm, not to mention the nature of the causal enquiry, which continues to generate debate almost twenty years after the adoption of the civil liability legislation.

${ }^{67}$ The Age (n 3) [207]. 